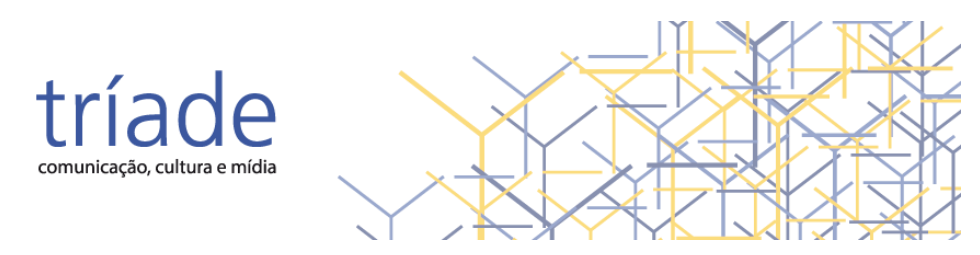

\title{
Novas construções de sentido em duas metáforas fotográficas
}

New constructions of sense in two photographic metaphors

Daniela Bracchi - Universidade Federal de Pernambuco I Caruaru I PE I Brasil bracchi@gmail.com_ORCID https://orcid.org/0000-0003-3247-0202

Resumo: Buscamos compreender neste artigo os efeitos de sentido construídos em duas metáforas visuais presentes em dois foto livros do artista Miguel Rio Branco. A primeira obra se apresenta como uma associação de duas imagens (um díptico), enquanto a segunda obra a ser analisada é uma imagem única. O referencial teórico utilizado busca auxiliar a investigação dessas duas obras enquanto metáforas visuais e é composto pelos estudos semióticos, a pesquisa sobre retórica visual do Groupe $\mu$ (1994) e pelas considerações do filósofo da arte Richard Wollheim (2002) sobre a metáfora pictórica. Desse modo, percorremos um caminho no qual as duas obras analisadas indicam dois modos diversos de produção de metáforas visuais e exploramos os efeitos de sentido construídos em cada uma delas.

Palavras-chave: Metáfora visual. Fotolivro. Miguel Rio Branco. Fotografia.

Abstract: In this article, we seek to understand the sense effects built on two visual metaphors present in two photobooks of the artist Miguel Rio Branco. The first work presents itself as an association of two images (a diptych), whereas the second work to be analyzed is a unique image. The applied theoretical reference seeks to help the investigation of these two works as visual metaphors and is composed of semiotic studies, the research on visual rhetoric of the Groupe $\mu$ (1994) and the considerations of the art philosopher Richard Wollheim (2002) about the pictorial metaphor. Thus, in the path we took, both analized works indicate two different modes of producing visual metaphors and we explore the sense effects constructed in each of them.

Keywords: Visual metaphor. Photobook. Miguel Rio Branco. Photography.

http://dx.doi.org/10.22484/2318-5694.2019v.7n15p.83-92

Recebido em dezembro 2018 - Aprovado em maio 2019 


\section{Introdução}

Buscamos analisar neste artigo duas obras do artista visual Miguel Rio Branco com o objetivo de melhor compreender a construção de metáforas visuais na fotografia contemporânea brasileira. Rio Branco nasce em 1946 na cidade de Las Palmas de Gran Canaria, Espanha, e inicia sua atividade artística como pintor na década de 1960. Mudou definitivamente para o Brasil na década de 1970, quando iniciou a produção de cinema experimental e fotografia, lançando seus primeiros fotolivros na década de 1980. É quando seu trabalho fotográfico subverte a produção vigente da época, ainda dividida entre um formalismo exacerbado advindo da vertente modernista e uma baixa exploração do potencial plástico da fotografia realizada pelos fotógrafos documentais. Rio Branco quebra padrões ao propor metáforas visuais de alta sensibilidade, construindo imagens únicas e dípticos que revelavam novas associações semânticas. Seu trabalho teve uma maior circulação na forma de fotolivros, justificando a importância da investigação sobre os novos modos de construção de sentidos metafóricos que o fotógrafo instaura nesse formato editorial.

Miguel Rio Branco é um fotógrafo com uma produção tão rica e sensível que os comentários sobre suas obras são facilmente encontrados no campo artístico. No entanto, por vezes, falta ao discurso artístico uma organização explícita do pensamento sobre a imagem, produzindo assim explicações que beiram a fruição intimista. Já os estudos históricos, cuja contribuição é evidentemente primordial, por vezes, deixam de lado a investigação sobre os modos de construção do sentido que são responsáveis pelo impacto visual dessas imagens.

Devemos considerar que os fotolivros de Rio Branco podem ser lidos como um grande texto formado por imagens em sucessão. A presença de dípticos e trípticos ao longo da narrativa visual chama a atenção por resgatar uma forma de composição visual bastante comum em épocas passadas, especialmente no período do Renascimento. Esse modo de expor as imagens realça as semelhanças plásticas entre as fotografias, de modo a manifestar uma associação entre dois universos semânticos distintos. Por isso, os dípticos do fotógrafo expõem a própria definição de metáfora: "uma biassociação, um repentino salto da imaginação criadora que associa duas ideias ou universos do discurso nunca antes conectados, colhendo-os 
numa nova síntese, que exprime revelação cognitiva e catarse emocional" (LOPES, 1987, p. 100).

Nos fotolivros de Rio Branco são explorados temas como a animalidade, o sofrimento, o prazer e a degradação humana. Isso se dá por meio de associações plásticas e figurativas que buscam aguçar a sensibilidade estética e criar novas cadeias interpretativas. Frequentemente, encontramos uma ordem sensível e pouco racional regendo o encadeamento das imagens, tal como no sonho e no devaneio. Essa estratégia tem sido descrita pelos críticos da obra de Rio Branco por meio de analogias com estratégias presentes na montagem cinematográfica, como aquelas apontadas por Eisenstein (1990). O cineasta soviético elucidou alguns dos efeitos de sentido criados pela sucessão de imagens, abrangendo não só a percepção do movimento a partir da sequência de formas e figuras, mas também o impacto emocional decorrente. No decorrer dos fotolivros de Rio Branco, encontramos diversas estratégias para a junção de fotografias que se aproximam dos métodos de montagem no cinema. Elas vão desde a lógica rítmica dos cortes cinematográficos efetuados a partir do tom emocional dos fragmentos (estratégia identificada por Eisenstein sob a denominação de montagem tonal) até a aproximação estritamente intelectual entre duas imagens.

No entanto, buscamos explorar neste artigo o potencial analítico das imagens de Rio Branco a partir de outros pontos de vista teóricos, mais distantes das teorias cinematográficas. Aproximamos o referencial teórico da filosofia da arte daquele da semiótica para compreender os modos pelos quais Rio Branco compõe metáforas visuais a partir da justaposição de duas diferentes imagens. Sabemos que os estudos sobre a metáfora são bastante desenvolvidos no campo da linguística e retórica. Por isso, para investigar a construção de metáforas visuais na obra de Rio Branco, são trazidos à tona os estudos do linguista brasileiro Edward Lopes (1987) e do semioticista francês Jacques Fontanille (1998), além das considerações realizadas por Zilberberg (2004) sobre as aproximações e afastamentos entre duas grandezas, que neste trabalho aplicamos às aproximações discursivas entre figuras numa sintaxe visual. O tema ganha ainda um maior aprofundamento com os estudos sobre retórica visual do Groupe $\mu$ (1994) e as considerações do filósofo da arte Richard Wollheim (2002) sobre a metáfora pictórica. 
Ao estudar as metáforas visuais, é preciso considerar, no entanto, a dificuldade em se transpor certas definições linguísticas para o campo visual, já que o âmbito linguístico apresenta um modo de presença marcado pela linearidade e sucessão, enquanto uma mensagem visual pode expor a simultaneidade de elementos em presença. Sendo assim, o que é caracterizado como uma substituição de elementos linguísticos pode adotar a forma de justaposição no visual. Os estudos do Groupe $\mu$ (1994, p. 245) apontam que a substituição linguística pode adotar, no visual, a forma de uma dupla presença dos termos constituintes da metáfora, borrando os limites entre comparação e metáfora, já que o que se manifestaria no sistema linguístico por meio de comparações e rimas pode ser dado no visual por meio de duplicidades icônicas e plásticas.

O impasse fica mais claro quando não se força uma terminologia linguística ao visual e se atém a uma descrição mais técnica da metáfora:

tropo obtido pela supressão-agregação de semas [...] veremos, assim, que fenômenos descritos frequentemente como 'metáforas visuais' provêm de mecanismos tão diferentes que não nos interessa em absoluto reuni-los com um termo que os unifica de maneira específica (GROUPE $\mu$, 1994, p. 260, tradução nossa).

Para compreendermos melhor a construção de sentido nas metáforas visuais formadas em fotolivros de Miguel Rio Branco, vamos nos debruçar sobre dois de seus mais famosos dípticos, cada um sendo parte de um fotolivro do famoso do artista.

\section{Duas metáforas visuais em análise}

Partiremos de uma dupla de imagens que aparece no primeiro ${ }^{1}$ fotolivro de Rio Branco, publicado no México com o título de Dulce sudor amargo, em 1985. As duas fotografias não têm título, de modo que é dúbia a sua interpretação enquanto

1 Os trabalhos publicados de Rio Branco, em ordem cronológica, são: Dulce sudor amargo (1985), Miguel Rio Branco (1988), Nakta (1996), Silent Book (1997), Miguel Rio Branco (1998), Entre Los Ojos (1999), Entre os olhos, o Deserto (2001), Gritos Surdos (2002), Plaisir la douleur (2005), Notes on Tides (2006), I Grandi Fotografi (2007), Tokyo (2009) e Você está feliz? (2012). Há uma certa disparidade sobre os livros lançados por Miguel Rio Branco, já que publicou em diversos lugares do mundo. O critério aqui utilizado respeitou o reconhecimento de autoria dessas obras conforme indicação no site do artista. 


\section{tríade}

algo construído para figurar em conjunto. No entanto, um olhar mais atento começa a perceber e colocar em relação as similaridades das duas figuras retratadas. Há uma identidade não só na parte do corpo retratada, mas também no tamanho (ainda que isso signifique mudar a escala em que cada imagem representa a figura) e no arranjo das cores, que forma uma padronagem de camuflagem na vestimenta feminina e também na plumagem da ave. A semelhança plástica entre as duas figuras constrói uma anáfora visual ${ }^{2}$ responsável pela relação de identidade entre os elementos capaz de construir uma aproximação metafórica.

Figura 1: Páginas 25 e 26 do livro Dulce Sudor Amargo, 1985
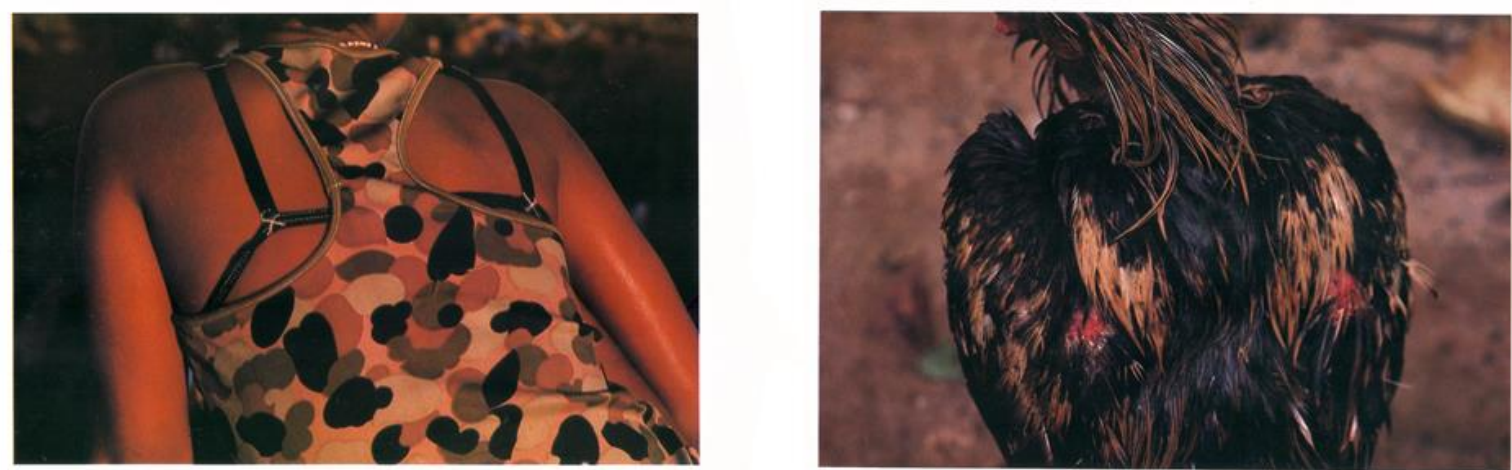

Fonte: RIO BRANCO, Miguel. Dulce sudor amargo. México: Fondo de Cultura Económica, 1985.

As semelhanças plásticas formam as rimas visuais, sugerindo a existência de uma relação semântica entre as figuras, assim como as rimas em uma poesia fazem o leitor buscar relações de sentido entre aquilo que se aproxima no nível fonético. As rimas plásticas são capazes de estabelecer nos dípticos a existência de um mesmo nível de comparação entre as imagens e facilitam a percepção de que uma narrativa pode se desenrolar entre elas.

A construção metafórica de uma mulher-galo é explicitada na imagem com a presença dos dois termos e convida o observador a refletir sobre os possíveis semantismos compartilhados entre essas duas figuras. Assim como um galo de briga que carrega suas marcas, as mulheres retratadas nos fotolivros de Rio Branco

2 Definida como "uma relação de identidade parcial que se estabelece no discurso, no eixo sintagmático, entre dois termos, servindo para vincular dois enunciados, dois parágrafos, etc." (GREIMAS; COURTÉS, 2008, p. 28, verbete anáfora). 
também mostram as marcas de uma vida sofrida, na qual o embate com o outro costuma deixar cicatrizes no corpo e ambos parecem condenados à luta e à resistência.

É interessante observar, ainda, que as duas imagens mantêm garantido o caráter icônico das figuras, sem perder seu sentido representativo usual, pois ainda identificamos que se trata de uma mulher e de um galo de briga. Desse modo, Miguel Rio Branco não nega o caráter representativo da fotografia, mas superpõe construções metafóricas que geram um sentido poético. Ele propõe criar outra relação entre as figuras que não é, necessariamente, a adoção do caminho contrário à figuratividade que se daria pela escolha da abstração.

Entende-se, ainda, que não existe a necessidade de um vínculo já estabelecido iconograficamente entre o que a fotografia mostra e o que ela metaforiza. Reside aí a possibilidade de inovação na construção do léxico de um fotógrafo e o caráter essencialmente improvisador da metáfora. Tal característica da metáfora já foi ressaltada por Wollheim (2002, p. 307), quando o filósofo britânico afirmou que o objetivo da metáfora pictórica é colocar o objeto metaforizado sob uma nova luz. As metáforas na forma de díptico podem ser entendidas ainda enquanto microssequências discursivas (FONTANILE, 1998) e uma das mais importantes estratégias para se inserir micronarrativas ao longo do fotolivro de forma a romper com uma narrativa linear, criando novos pontos de vista e novas associações semânticas ao longo da sequência imagética.

A justaposição das figuras do galo e da mulher na diagramação do fotolivro empresta à imagem da mulher um valor disfórico se considerarmos o sentido que a junção homem/animal têm ganhado no campo artístico. A construção do sentido de animalidade pela justaposição das figuras humanas e animais foi vista historicamente como odiosa e o híbrido homem/animal é apontado por Eco (2007, p. 34) como uma das primeiras formas de construção dos "feiamente" atrozes. Vale lembrar a variedade de exemplos presentes na mitologia clássica, como as sereias de Homero (compostas na parte superior de um busto de mulher e na parte inferior das formas de ave de rapina). Eram seres "assustadores, odiosos por serem híbridos que violam as leis das formas naturais" (ECO, 2007, p. 34). A junção de figuras humanas e animais cria a possibilidade de imaginação de outros corpos que fundem suas características individuais para compor um novo sentido. 


\section{tríade}

Entende-se, portanto, que a fotografia pode adotar uma composição na qual as duas imagens de um díptico podem apresentar elementos, tais como cor, forma e tamanho, que realizam uma mediação plástica ${ }^{3}$ entre as figuras. Desse modo, um ou mais elementos do plano da expressão passam a propor uma relação mais ambígua entre os temas presentes nas duas imagens do que aquela que seria formada se as fotografias fossem apresentadas separadamente. Para tanto, a repetição de figuras e formantes plásticos é decisiva. Segundo Greimas e Courtés (1986, p. 307, verbete metáfora), "as isotopias figurativas remetem quer a outras isotopias figurativas, quer a isotopias temáticas mais abstratas". As rimas visuais podem servir de semelhanças capazes de construir a base do relacionamento entre valores antagônicos como homem/animal, prazer/sofrimento, etc.

Mas, se o nível discursivo aceita qualquer tipo de justaposição figurativa, em um nível mais profundo, deve haver uma identidade mínima, mesmo entre os termos opostos. Desse modo, segundo Zilberberg (2004), há uma gradação das distâncias e aproximações possíveis entre os termos colocados numa metáfora (ou, no caso da fotografia, das figuras colocadas em relação) que pode ser definida de acordo com o grau de triagem (divergência semântica) e mistura (convergência semântica) dos valores observados.

Valores semânticos opostos podem ser aproximados sintaticamente por meio de reiterações plásticas, levantando a possibilidade de sua união semântica por meio de uma lógica concessiva ${ }^{4}$ que torna possível e desejável a conjunção de elementos apesar de uma impossibilidade tida como natural. Desse modo, a metáfora se mostra como um modo privilegiado de relação entre valores contrários e contraditórios, pois, segundo Zilberberg (2004), essa operação retórica se caracteriza pela suspensão da distância estabelecida entre os termos colocados em relação.

O semioticista francês aponta o fato da concessão possibilitar a criação de um efeito de novidade e subversão que interessa à construção do discurso artístico. No entanto, a distância entre os valores deve ser ponderada. A união de valores contrários ( $\mathrm{a}$ e b, tal como natureza $\mathrm{x}$ cultura, vida $\mathrm{x}$ morte, humano $\mathrm{x}$ animal etc.)

3 O termo é proposto pelo Groupe $\mu$ (1994).

4 A concessão valoriza a surpresa, unindo termos e valores semânticos contrários (embora a, entretanto b) em contraposição à lógica de junção implicativa, que une termos semânticos de acordo com uma previsibilidade lógica (se a, então b). 


\section{tríade}

pode ser "heroica, superlativa e excitante, ao passo que a conjunção entre subcontrários é prosaica, razoável e um tanto sem graça" (ZILBERBERG, 2004, p. 19).

Existiria, portanto, uma justa medida da associação entre contrários. Termos já muito próximos semanticamente podem produzir uma reiteração tediosa, assim como a falta de alguma identidade possível entre os termos revela uma impossibilidade de um desenvolvimento maior do sentido. A disjunção excessiva impede a construção do sentido no discurso, tornando claro o fato de que certo grau de semelhança deve estar na base de estabelecimento de toda diferença. Há, portanto, um traço comum capaz de ser depreendido mesmo nas relações de contradição entre valores semânticos de base e abre-se a possibilidade de estabelecimento de um termo complexo, que conjugaria esses contrários.

Desse modo, a semiótica se mostra capaz de trabalhar sob uma lógica concessiva, resgatando as influências de Hjelmslev (1975) e Brøndal (1986), com sua recusa do estrito binarismo lógico. De fato, uma das características marcantes dos grandes teóricos dinamarqueses da linguagem é a postulação do reconhecimento de organizações de tipo participativo, subjacentes às oposições exclusivas com que lida a lógica binária. Zilberberg (2006, p. 45) aponta ainda um caminho de valorização da concessão presente desde os estudos sobre Retórica. A convivência dos contrários presentes na forma de metáforas, metonímias e oxímoros indicaria uma antiga valorização da integração de opostos.

Já ao longo da história da arte, passa-se a perceber como cada vez mais interessante a presença da associação de contrários, entendendo-se a presença do diferente como base da criação da beleza. No entanto, cada texto visual merece uma análise minuciosa para estabelecer o modo como valores semânticos opostos podem ser aproximados.

No díptico analisado anteriormente, temos a construção de uma metáfora a partir da junção de duas imagens distintas, mas devemos considerar que associações metafóricas também podem ser formadas a partir da colocação em relação de duas figuras dentro da mesma fotografia. É o caso de nossa próxima imagem a ser analisada. 


\section{tríade}

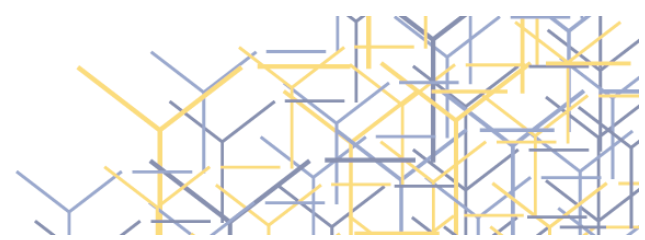

Figura 2: Miguel Rio Branco, Sem título, 1985.

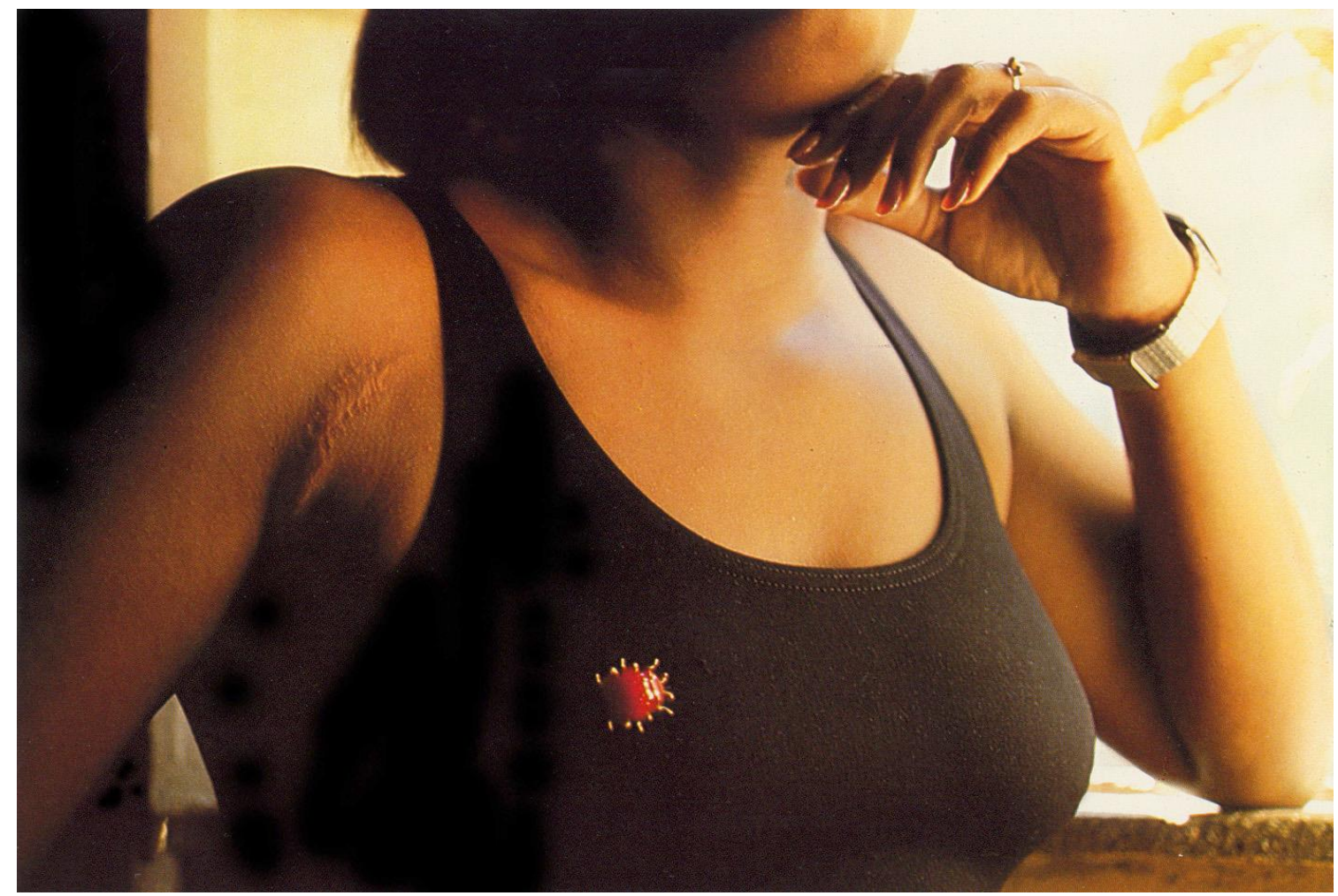

Fonte: RIO BRANCO, Miguel. Dulce sudor amargo. México: Fondo de Cultura Económica, 1985.

A imagem da Figura 2 apresenta um busto vestido no qual encontramos uma ressonância de cores: a cor preta da blusa faz sobressair a figura do broche de joaninha enquanto a cor vermelha de tal animal remete ao tom ocre da pele humana. Logo acima do broche, um pouco à esquerda, o leitor pode notar a semelhança entre a forma do animal e a cicatriz na axila da mulher, pois a proeminência das patas é reiterada nas marcas de pontos que margeiam a cicatriz.

O posicionamento do broche no corpo da modelo sugere ainda a presença externalizada do mamilo. O efeito de sentido gerado pela inserção nesta área do corpo de uma figura com as cores e formas similares a um mamilo é difícil de ser 


\section{tríade}

especificada. Se fosse uma pintura seria mais fácil afirmar que o pintor constrói uma cena que trata a sexualidade de maneira irreverente, mas aqui fica a dúvida.

Um observador familiarizado com a história da arte e com o papel do detalhe na leitura da imagem pode levar mais longe as aproximações semânticas entre a figura do inseto e a ideia de sexualidade trazida à tona pelo posicionamento do broche no local do mamilo. Isso porque outro inseto, a mosca, aparece recorrentemente em quadros do século $\mathrm{XV}$ e XVI como detalhe que atesta a capacidade do pintor em produzir cenas e retratos realistas, havendo casos em que o inseto também transita na ambiguidade entre o sentido de atestar o realismo e indicar uma marca sexual em figuras religiosas.

O historiador da arte Daniel Arasse (1996) explica que o pequeno animal também ganha um valor moral, pois possui um caráter nefasto (alimenta-se de restos, repousa sobre as carnes mortas etc.) e funciona em muitos quadros como um memento mori, lembrete da finitude da vida. No entanto, a joaninha presente na Figura 2 suplanta esse caráter sombrio. A força da cor e do seu posicionamento no corpo sublinha muito mais a ideia de desejo do que a de morte. Apenas um enunciatário com certo conhecimento sobre a história da arte poderia refazer 0 caráter dúbio do inseto, entre lembrete da mortalidade e marca da sexualidade.

Vale a pena lembrar uma famosa pintura na qual essa dubiedade é exposta. O quadro do pintor italiano Giovanni Santi (pai de Rafael Sanzio) apresenta o detalhe de uma mosca pintada sobre o corpo do Cristo ressuscitado.

Figura 3: Giovanni Santi, Cristo ressuscitado, 1490. 


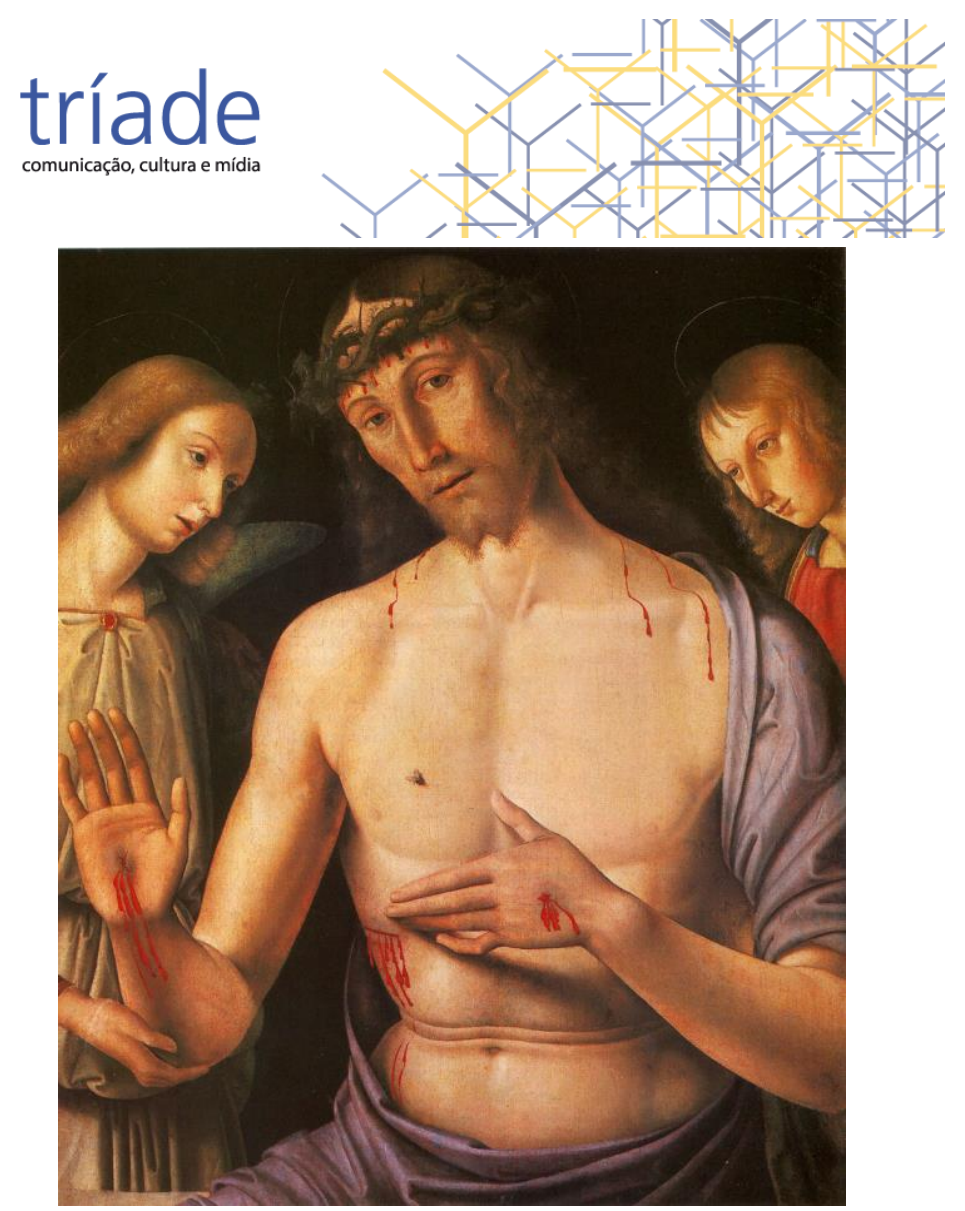

Fonte: https://www.the-athenaeum.org/art/detail.php?ID=242949 (Acesso em 27/11/2018)

O posicionamento da mão de Cristo sublinha a existência da mosca na cena. $O$ inseto evidencia as marcas do sofrimento que se fazem ver sobre a pele. Além disso, a sua localização instiga o olhar a se demorar sobre uma área erógena do corpo. Percebe-se que o detalhe destaca não apenas uma porção do espaço do quadro, mas também opera na temporalidade do olhar do enunciatário. $\mathrm{O}$ olho percorre a cena em busca de uma narrativa visual e o detalhe interrompe esse vagar, particulariza um momento em que o observador é convidado a interromper a construção de uma visão geral para estabelecer as relações entre o detalhe e a cena.

Tanto na pintura de Giovanni Santi quanto na fotografia de Rio Branco, o detalhe do inseto é responsável por criar um paralelismo entre a noção de prazer presente na exaltação de uma zona erotizada do corpo e o sentido de dor e sofrimento marcados na presença das marcas, ferimentos e cicatrizes localizadas próximas a essa área. Novas relações são estabelecidas a partir da observação de uma pequena porção da imagem, aproximando o detalhe da ideia de punctum, tal como o define Roland Barthes (1984). 
A parada do olhar sobre um espaço reduzido da imagem leva a uma maior aproximação do leitor à superfície do texto visual. O fotógrafo inscreve na imagem um convite para que o observador realize uma mudança das distâncias com as quais entra em contato com a imagem. Na fotografia, o leitor se encontra no papel indiscreto de se aproximar do local que ancora a sexualidade feminina quando precisa chegar o olhar mais perto para observar a figura que faz alusão ao mamilo. Aqui, a rima de formas tem um papel particularizante, que concentra a atenção do leitor nas figuras do animal e da cicatriz.

O fotógrafo realiza, portanto, uma espécie de programa de ação a ser cumprido pelo leitor. Já este último sente o repousar do olhar como um acidente do olho, segundo descrito por Arasse (1996, p. 244). O historiador de arte francês indica o detalhe como um acontecimento, uma descoberta, um êxtase do olhar. O destaque do detalhe em relação à cena é uma separação que tem a força de uma fissura, construindo um sentido muito mais da ordem do sensível do que do cognitivo ${ }^{5}$.

\section{Considerações finais}

Propomos retornar às imagens analisadas para realizarmos algumas considerações finais sobre possíveis sentidos metafóricos encontrados a partir da aproximação entre as figuras humanas e as figuras de animais. É interessante notar que não encontramos nas figuras humanas deste artigo a presença do rosto que individualize a pessoa retratada. Tal falta de particularização do ator do enunciado como alguém em específico favorece a construção do sentido de seres que unem a forma genérica de um corpo humano e o corpo de um animal.

A partir daí, uma possível aproximação entre o sentido do humano e do animal é construída plasticamente por meio da analogia de cores e formas. Percebemos, portanto, o papel da junção das duas fotografias primeiramente analisadas e da justaposição de rimas visuais presentes na segunda obra como sendo $o$ de construir híbridos humano/animal que sintetizam o sentido de resistência, dor e prazer vivido no contexto maior da narrativa do fotolivro.

5 Segundo Arasse (1996, p. 387), um valor que não é o de saber: "une 'valeur' qui n'a rien à voir avec un 'savoir". 
Não se deve esquecer, entretanto, que a exploração da ideia da animalidade do homem se tornou, ao longo da história da arte, um dos lugares comuns da corrente estética do surrealismo, numa referência simbólica à aproximação do corpo humano com a forma animal, presente no discurso religioso. É esse o sentido que Rosalind Krauss (2002) ressalta em seu estudo sobre a fotografia surrealista, pois os fotógrafos faziam constantemente referência à ideia do corpo humano pecaminoso como semelhante ao animal, segundo a lógica de que "não se pode mais ver o corpo como humano, pois ele pecou para se tornar um animal" (KRAUSS, 2002, p. 174). Numa forte referência à degradação e ao pecado, são os corpos habitantes do Maciel6, corpos de prostitutas, marginalizados, crianças a esmo e famílias pobres, que se assemelharão às formas dos mais variados animais.

As imagens aqui vistas não apresentam cenas leves e agradáveis e as figuras de cicatrizes na pele humana e machucados no corpo do galo de briga são passíveis de criar o pathos ${ }^{7}$ de um enunciatário incomodado. Ao mesmo tempo em que o leitor mostra-se interessado na narrativa ao folhear o fotolivro de onde essas imagens foram retiradas, ele não pode se colocar na posição de relaxamento e satisfação que cenas mais tranquilas, mais distanciadas e menos embativas provocariam.

As figuras aqui analisadas são dois momentos distintos presentes nas narrativas de dois fotolivros de Miguel Rio Branco. Na Figura 1 há a construção de efeitos de sentido criados a partir da colocação em relação de uma figura feminina com a de um galo de briga. Já na segunda figura, observamos que aproximações eidéticas dentro de uma mesma imagem nos possibilitou compreender melhor a construção de efeitos de sentido tanto de sexualidade (a partir do posicionamento da figura no local dos mamilos), quanto de resistência a partir das rimas entre partes do corpo do animal e a cicatriz no coro humano. A segunda figura permitiu explorar também o papel do detalhe na imagem, que possibilita a parada do olhar e a observação mais atenta de sentidos da imagem presentes em partes do corpo.

\section{Referências}

$6 \quad$ Área degradada do Pelourinho, em Salvador, onde Rio Branco produz as imagens de seu
primeiro fotolivro.
$7 \quad$ O termo se refere aos valores modais e tímicos suscitados no leitor pela imagem. Entende-se
que a fotografia desperta tanto um querer, dever, poder e saber no observador quanto paixões e
sensações relacionadas à imagem. 


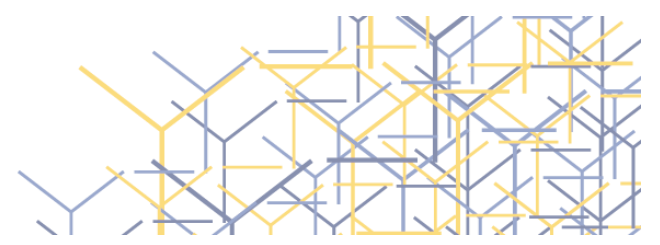

ARASSE, D. Le Détail: pour une histoire rapprochée de la peinture. Paris: Flammarion, 1996.

BARTHES, R. A Câmara Clara: nota sobre a fotografia. Rio de Janeiro: Nova Fronteira, 1984 (original francês de 1980).

BRøNDAL, V. Omnis et totus. In: Actes sémiotiques. Documents. Paris: Groupe de Recherches Sémio-Linguistiques. EHESS, CNRS, VIII, 72; 1986.

ECO, U. História da feiúra. Rio de Janeiro: Record, 2007.

EISENSTEIN, S. A forma do filme. Rio de Janeiro: Jorge Zahar, 1990.

FONTANILLE, J. Sémiotique du discours. Limoges: Presses Universitaire de Limoges, 1998.

GREIMAS, A. J; COURTÉS, J. Sémiotique. Dictionnaire raisonné de la théorie du langage. Tomo 2. Paris: Hachette, 1986.

GREIMAS, A. J; COURTÉS, J. Dicionário de Semiótica. São Paulo: Contexto, 2008 (original francês de 1979).

GROUPE $\mu$. Tratado del signo visual. Madrid: Ediciones Cátedra, 1994.

HJELMSLEV. L. Prolegômenos a uma teoria da linguagem. $2^{a}$ ed. São Paulo: Perspectiva, 1975.

KRAUSS, R. O Fotográfico. Trad. de Anne Marie Davee. Barcelona: Editorial Gustavo Gili, 2002.

LOPES, E. Metáfora: da retórica à semiótica. $2^{2}$ ed. São Paulo: Atual, 1987.

WOLLHEIM, R. A pintura como arte. Trad. de Vera Pereira. São Paulo: Cosac Naify, 2002 (original inglês de 1987).

ZILBERBERG, C. "As condições semióticas da mestiçagem". In: CAÑIZAL, E. P. \& CAETANO, K. E. (Orgs.) $O$ olhar à deriva: mídia, significação e cultura. São Paulo: Annablume, 2004.

ZILBERBERG, C. Razão e poética do sentido. São Paulo: EDUSP, 2006. 